Información farmacológica

POLÍTICA SOBRE MEDICAMENTOS

ENMIENDAS A LA ROTULACIÓN

REACCIONES ADVERSAS

DECISIONES DIVERSAS

PUBLICACIONES
Registro de productos y establecimiento de la Línea Roja de la DIGEMID en el Perú; Ley Reformatoria al Código de la Salud y decreto sobre acreditación de laboratorios de análisis en Ecuador; ley de modernización de la FDA; anuncios sobre fármacos en los medios de difusión; creación de la Comisión Nacional de Medicamentos Genéricos en Venezuela.

Ácido acetilsalicílico y paracetamol; irinotecán; terfenadina; tramadol; trihexilfenidil; benzodiazepinas durante el embarazo y la lactancia; benzodiazepinas inyectables; sobredosis de cisplatino; antiinflamatorios no esteroides.

Clormezanona; laxantes a base de fenolftaleína; laxantes a base de dantrón; lisina amidotrizoato en medios de contraste iónicos; metamizol sódico; pemolina; carbonato de hidrógeno sódico; seldane y terfenadina genérica; albúmina de suero humano; suplemento dietético "Buda durmiente"; fenfluramina y dexfenfluramina.

Indicación sobre uso en pacientes pediátricos; indicación sobre uso en pacientes geriátricos; lamotrigina; terfenadina y terfenadina/pseudoefedrina; difenhidramina; Duract $^{\circledR}$; aparatos a base de látex; condones de látex.

Inhibidores de la proteasa de VIH; paracetamol; cloruro de suxametonio; ácido alendrónico; ginecomastia inducida por fármacos diversos; metotrexato; riesgos de sustituir un medicamento por otro; Hismana ${ }^{\circledR}$; jalea real; somatropina; terbinafina; dispositivos médicos impregnados de clorhexidina; amiodarona y cambios pulmonares.

Pseudoefedrina, fenilpropanolamina y efedrina; fluorocarburos clorados; sistemas de rayos láser de marca Excimer ${ }^{\circledR}$; estuches para la detección de antígenos de estreptococos del grupo B; pruebas para aplicación doméstica; productos en solución inhalable; rifabutina; comprimidos de acetato cálcico con aluminio; talidomida; control especial de recetas para esteroides anabólicos; régimen propuesto para la administración del butirfanol; disponibilidad sin receta de la histamina $\mathrm{H}_{2}$.

Quality assurance of pharmaceuticals, vol. 1, World Health Organization, Geneva, 1997; Reforma del sector farmacéutico y del sector salud en las Américas: una perspectiva económica, Organización Panamericana de la Salud, Washington, DC, 1998.

\section{POLÍTICA SOBRE MEDICAMENTOS}

\section{Registro de productos y establecimiento de la Línea Roja de la DIGEMID (Perú)}

Con fecha 31 de julio de 1997 se publicó en la Gaceta Oficial del
Acuerdo de Cartagena No. 284 la Decisión 418 sobre la expedición de registro o inscripción sanitaria de productos con riesgo sanitario, cuyos artículos destacan, entre otras cosas, que en caso de productos registrados en un país miembro que requieran de registro o incripción sanitaria para su comercialización, las autoridades nacio- nales competentes deberán pronunciarse dentro de los 30 días hábiles posteriores a la presentación de la solicitud correspondiente. Asimismo el interesado debe responder a las observaciones formuladas por la autoridad dentro de los 15 días hábiles posteriores a su recepción y, una vez recibida la respuesta, la autoridad nacional debe 
dictaminar el otorgamiento del registro o la inscripción sanitaria en un plazo no mayor de 15 días. Esta decisión entró en vigencia el 1 de enero de 1998.

La Dirección de Medicamentos, Insumos y Drogas (DIGEMID) del Ministerio de Salud estableció la Línea Roja, subprograma destinado a la atención al consumidor, que tiene por objeto recibir denuncias sobre irregularidades en la calidad y comercialización de los medicamentos, cosméticos, galénicos, materiales médicos y quirúrgicos, y productos naturales de uso medicinal y homeopático.

\section{Ley Reformatoria al Código de la Salud y decreto sobre acreditación de laboratorios de análisis (Ecuador)}

Con fecha 6 de agosto de 1997 se publicó en el Registro Oficial, órgano del Gobierno, la Ley Reformatoria al Código de la Salud. En dicha Ley se han agregado, entre otros, los siguientes incisos:

Artículo 1. "La receta médica, además del nombre comercial, obligatoriamente deberá contener el nombre genérico del medicamento".

Artículo 2. "Quien lo expenda deberá informar al comprador sobre la existencia del genérico y su precio. Será obligatorio disponer de un cuadro básico de medicamentos genéricos".

Artículo 3. Todas las medicinas y medicamentos de uso humano que se expendan, comercialicen, o ambos en el territorio ecuatoriano deberán contener claramente indicado en su etiqueta tanto el nombre comercial como el genérico, en un tamaño razonable y en letra claramente visible, que permita la individualización y selección por parte del usuario.

Artículo 4. El Ministerio de Salud Pública controlará y sancionará con la suspensión del permiso de funcionamiento a los establecimientos que expendan medicamentos con receta en las que no conste el nombre genérico de los productos.

Con fecha 19 de septiembre de 1997 se publicó en el Registro Oficial el
Decreto sobre el Reglamento para "acreditar la participación de laboratorios de análisis y control de calidad de universidades, escuelas politécnicas y empresas privadas en la elaboración de los análisis requeridos para la emisión del registro sanitario", y establece que la acreditación de laboratorios de análisis y control de calidad de empresas particulares, universidades y escuelas politécnicas será solicitada al Ministerio de Comercio Exterior, Industrialización y Pesca, cumpliendo los requisitos que para el efecto determine el Comité Interinstitucional de Acreditación.

Los análisis de laboratorio requeridos previamente para la expedición del Registro Sanitario los deberán realizar el Instituto Nacional de Higiene y Medicina Tropical, sus regionales, o laboratorios de análisis y control de calidad nacionales, debidamente acreditados, pertenecientes a universidades, escuelas politécnicas o empresas privadas y debidamente acreditados. Se encuentran además en el Decreto las reformas de algunas disposiciones previas sobre la materia.

\section{Ley de modernización de la FDA (Estados Unidos de América)}

En los Estados Unidos con fecha 21 de noviembre de 1997 se promulgó la ley para reforzar y modernizar las actividades de la Administración de Alimentos y Medicamentos (FDA). Los puntos claves de esta ley incluyen la aprobación de productos en un período más corto y la simplificación del proceso y reducción de los requisitos de registro de medicamentos nuevos.

\section{Anuncios en los medios de difusión: se publica documento de orientación preliminar (Estados Unidos de América)}

La Administración de Alimentos y Medicamentos (FDA) ha anunciado que está a disposición de los interesados un documento de orientación preliminar titulado Consumer-directed broadcast advertisements, que contiene información, entre otras cosas, sobre la forma de anunciar los fármacos obtenibles con receta médica por los medios de difusión, como los sistemas de comunicación por radio, televisión, o teléfono.

Todos los anuncios de fármacos obtenibles con receta médica que aparezcan en esos medios deben contener información sobre los principales riesgos de dichos productos. En lugar de resumir la información en el momento del anuncio, el patrocinador puede hacer lo indicado para que se divulgue el contenido autorizado para el rótulo del envase durante la presentación en los medios citados.

Se reconoce, con respecto al requisito de "hacer lo indicado", que los anuncios en los medios de difusión no dan suficiente tiempo para presentar y comunicar debidamente los detalles que se incluirían en un mensaje resumido. Más bien, se especifica que la presentación de los riesgos más importantes del producto anunciado más la provisión adecuada de información más minuciosa bastan para cumplir con los reglamentos que exigen que se divulgue cualquier riesgo.

Los interesados en obtener ejemplares del documento de orientación pueden dirigirse a: Drug Information Branch (HFD-210), Center for Drug Evaluation and Research, FDA, 5600 Fishers Lane, Rockville, MD 20857, EUA. La carta debe acompañarse de una etiqueta engomada marcada con el nombre del destinatario. El documento también puede pedirse a la siguiente dirección de Internet: http: //www.fda.gov/cder/guidance/htm

\section{Creación de la Comisión Nacional de Medicamentos Genéricos (Venezuela)}

Con el Decreto No. 2.433 de fecha 25 de febrero de 1998, publicado en la Gaceta Oficial de la República de Venezuela el 18 de marzo de 1998, se creó con carácter permanente la Comisión Nacional de Medicamentos Genéricos, cuyo propósito es asesorar al Ejecutivo Nacional de Venezuela en la implanta- 
ción, seguimiento, evaluación y control de las actividades del Programa de Producción de Medicamentos Genéricos y en la comercialización de dichos medicamentos.

\section{USO RACIONAL}

\section{Ácido acetilsalicílico y paracetamol: control por medio de receta (Reino Unido)}

El ácido acetilsalicílico y el paracetamol se han sometido a control por medio de receta, con algunas exenciones que permiten su venta libre en cantidades limitadas. Los cambios entrarán en vigor el 16 de septiembre de 1998 con el fin de dar tiempo a que se agoten las existencias.

Se exigirá a las farmacias que se abstengan de vender más de 100 tabletas o cápsulas de ácido acetilsalicílico o paracetamol a la vez. Las exenciones se aplican solamente a los paquetes de 32 tabletas y cápsulas o menos y a las formas de presentación y potencias indicadas a continuación:

- ácido acetilsalicílico: potencia máxima, $325 \mathrm{mg}$

- paracetamol: $120 \mathrm{mg}$ para los niños menores de 12 años y $500 \mathrm{mg}$ para los adultos y los niños de 12 años o más.

En ambos casos, las nuevas restricciones se aplicarán solamente a las tabletas y cápsulas no efervescentes. Una exención general del control por medio de receta cubrirá a todas las otras formas de presentación.

Se han introducido para la venta al público en general (por ejemplo, en supermercados) nuevos paquetes de un tamaño máximo de 16 tabletas y cápsulas no efervescentes (que antes tenían 25); de preparaciones líquidas de paracetamol de un máximo de $160 \mathrm{~mL}$ y con una potencia máxima de 2,5\% para personas de 12 años o más; y de 20 dosis de un máximo de $5 \mathrm{~mL}$ con una potencia máxima de $2,4 \%$ (dosis máxima de $480 \mathrm{mg}$ y dosis diaria máxima de $1920 \mathrm{mg}$ ) para niños menores de 12 años.

\section{Irinotecán: enmienda de la hoja de información para incluir advertencias y precauciones para el uso (Japón)}

La Oficina de Seguridad Farmacéutica y Médica examinó la hoja informativa del irinotecán (Campto ${ }^{\circledR}$ : Daiichi Pharmaceuticals, Yakult), agente antineoplásico inyectable, para recalcar la necesidad de ejercer una cuidadosa vigilancia especialmente durante las 2 semanas posteriores a la administración.

Esta medida se tomó después de que los titulares de la licencia anunciaron en una circular enviada a los médicos que durante los 3 años transcurridos desde que se introdujo el irinotecán al mercado, 42 de 5400 pacientes (alrededor de $0,8 \%$ ) tratados con ese fármaco habían muerto de afecciones posiblemente relacionadas con el tratamiento. La mayoría de las defunciones parecen haberse producido sobre todo por mielosupresión causada por el producto, una reacción adversa conocida.

El producto debe ser empleado solamente por médicos expertos y después de que el paciente haya dado su consentimiento fundamentado. Es preciso confirmar el cuadro hemático del paciente y suspender cualquier administración programada si se sospecha que el paciente tiene mielosupresión. Se debe observar al paciente con cuidado para determinar si tiene alguna anomalía hemática.

\section{Terfenadina: medidas restrictivas (Irlanda)}

La Junta Irlandesa de Medicamentos ha decidido cambiar, con efecto inmediato, la clasificación de la terfenadina a la de medicamento recetado solamente por causa de la creciente complejidad de las precauciones necesarias para asegurar su uso inocuo.

Se recuerda a los prescriptores que tengan en cuenta las siguientes precauciones y advertencias:

- Los pacientes con enfermedades del corazón o del hígado no deben usar terfenadina.
- No se debe administrar más de la dosis recomendada (120 mg diarios para los adultos).

- La terfenadina no debe tomarse con jugo de toronja.

- Se ha notificado interacción con los siguientes medicamentos:

- ketoconazol, itraconazol y otros agentes antimicóticos afines a base de imidazol

- eritromicina, claritromicina y otros antibióticos macrólidos afines.

Tramadol: no se recomienda como analgésico de primera línea para aliviar el dolor moderado (Noruega)

La Administración Noruega de Fiscalización de Medicamentos ha recomendado abstenerse de emplear tramadol (Nobligan ${ }^{\circledR}$ : Grünenthal), autorizado en ese país para aliviar el dolor moderado, como analgésico de primera línea. Su empleo es cada vez mayor en todo el mundo y los informes de reacciones medicamentosas adversas nuevas e importantes han sido motivo de preocupación. El Comité estima ahora que al ponderar las reacciones adversas frente a la eficacia, el tramadol parece ser un producto menos apropiado como analgésico de primera línea.

\section{Tramadol: reclasificado (Omán)}

El Ministerio de Salud ha decidido clasificar las preparaciones que contienen tramadol como analgésicos opioides y determinado que, como tales, deben suministrarse solo con receta "amarilla" de las clínicas y policlínicas particulares y "verde" de los Servicios de Salud Pública. Además, su importación, almacenamiento, reparto, distribución, etc., se han sometido a las condiciones aplicables a los medicamentos psicotrópicos catalogados en los cuadros 3 y 4 de las sustancias psicotrópicas objeto de fiscalización internacional.

\section{Trihexifenidilo: reclasificado (Omán)}

El Ministerio de Salud ha decidido clasificar las preparaciones que contie- 
nen trihexifenidilo (benzhexol) en el grupo de sustancias no psicotrópicas fiscalizadas.

\section{Benzodiazepinas durante el embarazo y la lactancia: se recuerda la necesidad de evitarlas (Reino Unido)}

El Comité de Inocuidad de los Medicamentos ha enviado un recordatorio a efectos de que el uso de benzodiazepinas debe evitarse durante el embarazo y la lactancia. Se destacaron los siguientes puntos:

- Las benzodiazepinas cruzan la placenta y hay un riesgo de efectos adversos para el feto. Si se administran en dosis altas durante los últimos meses del embarazo o el parto, el recién nacido puede sufrir efectos tales como hipotermia, hipotonía y depresión respiratoria moderada.

- Los lactantes cuyas madres hayan tomado benzodiazepinas por un tiempo prolongado durante las últimas etapas del embarazo pueden presentar dependencia física y estar expuestos al riesgo de manifestar síntomas de abstinencia en el período posnatal (irritabilidad o dificultad con la alimentación).

- Si se receta una benzodiazepina a una mujer en edad de procrear, se le debe aconsejar que se comunique con su médico para que le indique cuándo debe descontinuar el medicamento si se propone quedar embarazada o sospecha que está en ese estado.

- Puesto que las benzodiazepinas se excretan en la leche materna, no se deben dar a las madres lactantes.

\section{Errores de medicación: pautas para las benzodiazepinas inyectables (Estados Unidos de América)}

Después de recibir un informe de un error de medicación, el Consejo Nacional de Coordinación para la Notificación y Prevención de Errores de Medicación ha recomendado pautas para las benzodiazepinas inyectables. El informe citó un incidente en que continuó observándose una orden de administrar lorazepam a una dosis de " 2 mg IV q 2 horas" para tratar las convulsiones sufridas por un paciente internado en la unidad de cuidados intensivos, después de trasladarlo a una unidad de atención regular.

El médico no especificó que la receta era para uso PRN (pro re nata, cuando se necesite) ni citó el número máximo de dosis y, como resultado, el paciente recibió nueve dosis de $2 \mathrm{mg}$. Puesto que los signos vitales se observaron con menos frecuencia en la unidad de atención regular, el paciente sufrió primero depresión respiratoria, luego paro cardíaco, y falleció.

Como consecuencia de este incidente, el hospital ha formulado una política para la administración de benzodiazepinas inyectables, aparte de la relativa a sedación consciente, que comprende lo siguiente:

- No se aceptan recetas telefónicas de benzodiazepinas intravenosas.

- Los pacientes que reciban benzodiazepinas inyectables deben vigilarse estrictamente, según la política de enfermería de la unidad específica.

- Las infusiones de benzodiazepina solo pueden administrarse en la unidad de cuidados intensivos y van acompañadas de una orden de supresión automática a las 24 horas.

- Los pacientes mayores de 65 años o con otros factores de riesgo, como administración simultánea de depresivos respiratorios (por ejemplo analgésicos narcóticos), insuficiencia hepática o renal, inestabilidad cardiovascular o insuficiencia pulmonar, reciben la mitad de la dosis establecida en los límites fijados en la política. También hay que vigilarlos con más atención.

- El flumazenilo se encuentra disponible en todos los envases citados en el código.

\section{Errores de medicación: advertencia especial sobre las dosis excesivas de cisplatino (Estados Unidos de América)}

El Instituto de Prácticas de Medicación Inocua ha hecho una advertencia especial a raíz de la muerte de un niño de 10 meses después de recibir 204 mg de Platinol $^{\circledR}$ (cisplatino) en lugar de 20,4 mg. Los informes indican que el médico prescriptor omitió la coma decimal y el personal de enfermería y de farmacia no reconoció la dosis excesiva.

Con el fin de evitar esos incidentes, Bristol-Myers Squibb, fabricante de Platinol ${ }^{\circledR}$, enmendó hace poco la etiqueta del envase y agregó que "Raras veces se usan dosis de cisplatino de más de $100 \mathrm{mg} / \mathrm{m}^{2}$ cada 3 o 4 semanas".

Este caso indica la necesidad crítica de observar las siguientes medidas de seguridad al emplear cisplatino:

- Considere la posibilidad de establecer el principio de redondear todas las dosis de medicamentos antineoplásicos de más de $10 \mathrm{mg}$ al número entero más próximo. Eso reviste particular importancia en pacientes pediátricos. En este caso, la cantidad de 0,4 $\mathrm{mg}$ era intrascendente; de haberse escrito $20 \mathrm{mg}$, se habría evitado el accidente.

- Se debe exigir tanto la dosis diaria calculada como la dosis basada en $\mathrm{mg} / \mathrm{kg}$ o $\mathrm{mg} / \mathrm{m}^{2}$ para la administración a pacientes pediátricos. Esto permite verificar la dosis y facilita el reconocimiento de las dosis recetadas incorrectamente. Conviene usar formularios uniformes para las recetas de quimioterapia contra el cáncer para el registro "obligatorio" de la información exigida, la superficie corporal (edad y peso de los niños) y otra información clínica esencial.

- Es indispensable revisar las recetas de medicamentos en el computador para detectar cualquier dosis excesiva que los médicos puedan pasar por alto accidentalmente. Muchos sistemas de computación tienen esa característica (incluso los computadores autónomos), pero no siempre se registran en el sistema los parámetros de dosificación necesarios.

- Los médicos, enfermeras y farmacéuticos inexpertos deben hacer refrendar su trabajo de personas entendidas en la materia (por ejemplo, si el personal de planta escribe la 
receta, el médico de cabecera deberá refrendarla).

- Conviene realizar al menos sesiones anuales de educación en el servicio sobre errores médicos a las que deberá asistir todo el personal clínico.

Los antiinflamatorios no esteroides, incluido el ácido acetilsalicílico: marco propuesto basado en el riesgo (Nueva Zelandia)

Después de recibir varias propuestas para reclasificar ciertos antiinflamatorios no esteroides (AINE) de administración oral, el Comité de Clasificación Médica ha examinado todos los AINE con miras a establecer un sistema coherente en lo que respecta a clasificación, determinación del tamaño del empaque, advertencias y consejo a los consumidores con el fin de promover el uso racional e inocuo de esos medicamentos. Como consecuencia, el Ministerio de Salud ha consultado a los profesionales de la salud sobre la idoneidad de un marco propuesto basado en el riesgo, preparado con varios "puntos de referencia" de acuerdo con la toxicidad gastrointestinal, y ha propuesto acceso limitado de conformidad con esa evaluación.

\section{RETIROS DEL MERCADO}

\section{Clormezanona: retiro del mercado (Alemania)}

Después de que Sanofi Winthrop decidió retirar del mercado mundial los productos que contienen el relajante muscular clormezanona (Tranco$\mathrm{pal}^{\circledR}$ ) y de que los fabricantes del producto genérico tomaron ulteriormente una medida similar, el Instituto Federal de Medicamentos y Dispositivos Médicos ha cancelado ahora la autorización de venta de todos los productos medicinales a base de clormezanona. Esas medidas se tomaron tras descubrirse un riesgo de reacciones cutáneas y hepatotoxicidad graves como consecuencia del uso de clormezanona. Ahora ya no queda ningún producto de esa clase en el mercado.

\section{Laxantes a base de fenolftaleína: retiro voluntario}

Después de recibir el aviso No. 65 de DRS sobre las medidas tomadas por los Estados Unidos de América y Francia para retirar del mercado los laxantes a base de fenolftaleína por causa de la preocupación por su posible genotoxicidad y carcinogenicidad, se han tomado las siguientes medidas.

Canadá. Después de analizar los riesgos y beneficios del uso de laxantes a base de fenolftaleína, el Departamento de Salud del Canadá ha determinado que existe un riesgo de que dicho producto cause cáncer en el ser humano; por ende, se revocará la autorización de venta y distribución.

Comisión Europea. En una reunión del Grupo de Trabajo sobre Farmacovigilancia celebrada en septiembre de 1997 se indicó que las autoridades nacionales competentes estaban considerando la posibilidad de retirar la fenolftaleína del mercado inmediatamente o discutiendo con los correspondientes titulares de la autorización de venta el retiro voluntario hasta el nivel de mayoristas. Si dichos titulares no pudieran llegar a un acuerdo sobre una medida voluntaria, las autoridades nacionales competentes considerarían la posibilidad de retirar los productos del mercado.

Japón. Los fabricantes ha retirado voluntariamente del mercado los productos que contienen fenolftaleína.

\section{Laxantes a base de dantrón: retiro voluntario (Canadá)}

Después de analizar los riesgos y beneficios del uso de laxantes estimulantes a base de dantrón, el Departamento de Salud del Canadá ha determinado que el dantrón es un carcinógeno genotóxico para los animales y que los riesgos de usar esos productos son superiores a los benefi- cios terapéuticos. El dantrón es una antraquinona sintética $\mathrm{y}$, aunque no hay pruebas directas de que haya causado cáncer en el ser humano, puede ser carcinógeno. Los fabricantes han dejado de vender esos productos voluntariamente.

\section{Amidotrizoato de lisina en medios de contraste iónicos: retiro del mercado (Alemania)}

El Instituto Federal de Medicamentos y Dispositivos Médicos ha retirado la autorización de venta de un medio de contraste iónico a base de amidotrizoato de lisina (Peritrast ${ }^{\circledR}$ $180 / 36 \%$ ), puesto que varios nuevos estudios a gran escala demuestran que los medios de contraste no iónicos de baja osmolaridad acarrean un riesgo mucho menor que los de contraste iónicos de alta osmolaridad, incluso Peritrast $^{\circledR}-180 / 36 \%$ y, por ende, ya no se puede justificar el uso de esos productos.

\section{Metamizol sódico: prohibido (Nepal)}

Las autoridades sanitarias han prohibido la importación, fabricación, venta, distribución y almacenamiento de metamizol sódico solo o en combinación con otros productos. Esa medida se ha tomado por la preocupación expresada con respecto a la inocuidad de este producto.

\section{Pemolina: retiro del mercado por hepatotoxicidad (Reino Unido)}

El Comité de Inocuidad de los Medicamentos ha retirado del mercado la pemolina (Volital ${ }^{\circledR}$ : LAB), recomendada para el tratamiento del síndrome hipercinético, por causa de informes de hepatotoxicidad grave. A pesar de su uso limitado, en los Estados Unidos de América se han notificado 33 reacciones hepáticas graves, seis de las cuales fueron mortales y dos exigieron transplante de hígado. 
Son pocas las pruebas de la eficacia de la pemolina para el tratamiento del síndrome hipercinético y en ensayos clínicos apropiados no se ha demostrado a cabalidad que el producto sea eficaz para los pacientes que han dejado de responder a otros fármacos. Por ende, el Comité estima ahora que los riesgos del tratamiento son mayores que los beneficios. Sin embargo, el fabricante facilitará el producto a cada paciente que lo solicite.

\section{Bicarbonato de sodio (de uso pediátrico): prohibido (Nepal)}

Las autoridades sanitarias han prohibido la importación, fabricación, venta, distribución y almacenamiento de bicarbonato de sodio en formulaciones líquidas de uso pediátrico. Esa medida se ha tomado por la preocupación expresada con respecto a la inocuidad de este producto.

\section{Seldane y terfenadina ${ }^{\circledR}$ genérica: retiro del mercado (Estados Unidos de América)}

Las compañías Hoescht Marion Roussel y Baker Norton Pharmaceuticals han descontinuado voluntariamente la distribución y venta de todas las líneas de productos antihistamínicos a base de terfenadina en los Estados Unidos de América. Los productos a base de terfenadina, como Seldane ${ }^{\circledR}$ y Seldane-D ${ }^{\circledR}$, han causado problemas cardíacos raros pero graves cuando se toman con algunos otros fármacos, incluso con ciertos antibióticos y antimicóticos.

En enero de 1997, la FDA propuso el retiro del mercado de todos los productos de terfenadina por haberse autorizado la venta de otro medicamento más inocuo: Allegra ${ }^{\circledR}$ (clorhidrato de fexofenadina). El clorhidrato de fexofenadina reporta exactamente los mismos beneficios que la terfenadina, pero no causa ninguna afección cardíaca potencialmente mortal cuando se toma con algunos otros medicamentos comúnmente recetados. En ese entonces, la FDA aconsejó a los pacientes que estuvieran tomando Seldane ${ }^{\circledR}$, Seldane- $\mathrm{D}^{\circledR}$ y productos genéricos de terfenadina que consultaran a sus dispensadores de atención de salud sobre la posibilidad de cambiar a otros productos. Después de la autorización de venta de Allegra$\mathrm{D}^{\circledR}$ en diciembre de 1997 y con la autorización previa de Allegra ${ }^{\circledR}$, Hoescht Marion Roussel anunció sus planes de descontinuar la distribución y venta de los predecesores de esos fármacos, Seldane ${ }^{\circledR}$ y Seldane-D ${ }^{\circledR}$, con efectos a partir del 1 de febrero. Asimismo, la empresa Baker Norton Pharmaceuticals, fabricante de terfenadina genérica, también ha descontinuado la distribución y venta de este producto en los Estados Unidos de América. Como resultado, los productos que contienen terfenadina pronto desaparecerán de las farmacias a medida que se agoten las existencias. La FDA recuerda a los consumidores y a los dispensadores de atención de salud usuarios de esos productos que existen otros fármacos igualmente inocuos y eficaces. Dicha entidad seguirá haciendo los trámites administrativos pertinentes para el retiro permanente de todos los productos a base de terfenadina.

\section{Seroalbúmina humana: retiro de varios lotes por posible contaminación con el virus de la nueva forma variante de la enfermedad de Creutzfeldt-Jakob (Reino Unido)}

Por consejo del Organismo de Fiscalización de Medicamentos, el proveedor del Reino Unido ha retirado del mercado tres lotes de seroalbúmina humana (Amerscan Pulmonate II Technetium Lung Agent $^{\circledR}$ : Nycomed Amersham) porque la información acopiada después de una donación reveló que se había emitido un diagnóstico ulterior de la nueva forma variante de la enfermedad de Creutzfeldt-Jakob a un donante de sangre.

Los tres lotes en cuestión corresponden a los números 548, 554 y 556 y constan de estuches de cinco viales. La com- pañía ha recomendado también retirar el producto en los países a los que ha sido exportado. Esta medida se adoptó como precaución, ya que no hay pruebas de que la enfermedad de Creutzfeldt-Jakob haya sido transmitida en algún momento por la sangre o los hemoderivados. No obstante, la nueva forma variante de la enfermedad parece tener características distintas de las que tiene la forma clásica. Sobre la base de las pruebas disponibles actualmente, no puede saberse a ciencia cierta que no sea transmitida por la sangre o sus derivados. Por consiguiente, la retirada de estos lotes de albúmina se estimó una medida de precaución prudente.

\section{La FDA desaconseja el consumo del suplemento alimentario "Buda durmiente"}

La Administración de Alimentos y Medicamentos (FDA) ha advertido a los consumidores que se abstengan de comprar o consumir el producto llamado "Buda durmiente". Se vende como suplemento alimentario y contiene un ingrediente empleado en los medicamentos recetados, omitido de la etiqueta, que puede acarrear riesgos para la salud. Tampoco se ha presentado a la FDA para examen ni autorización de las formas de empleo para las cuales se vende.

El Buda durmiente se fabrica en cápsulas en China y la etiqueta indica que es importado y distribuido por Treasure Box Products, Inc., de Burnaby, Columbia Británica, Canadá. El producto se promueve para tratar el insomnio y el desasosiego y como sustituto natural de los sedantes recetados.

La FDA ha determinado que el producto contiene estazolam, sedante de la familia de las benzodiazepinas e ingrediente farmacéutico cuya potencia exige receta. Se sabe que el estazolam causa graves efectos colaterales, incluso daño al feto si una mujer embarazada consume el producto.

Además, como se trata de un sedante, acarrea un riesgo particular para los consumidores que están bajo su efecto mientras manejan un vehículo, 
trabajan con maquinaria pesada $\mathrm{O}$ toman otros sedantes o alcohol.

La FDA no ha recibido ningún informe de lesiones ni reacciones adversas causadas por este producto. No obstante, todos los consumidores, sobre todo, las mujeres embarazadas, deben conocer bien sus riesgos.

Como consecuencia de las pruebas hechas por los Gobiernos de los Estados Unidos de América y del Canadá, Treasure Box Products Inc. ha comenzado a retirar voluntariamente del mercado todos los productos vendidos en los EUA. La FDA, junto con la Dirección de Productos Terapéuticos del Canadá, observará dicho retiro.

Los consumidores que hayan usado ese producto y tengan alguna preocupación de índole médica deben consultar a sus dispensadores de atención de salud.

\section{Retirada de los anorexígenos fenfluramina y dexfenfluramina (España)}

La Dirección General de Farmacia y Productos Sanitarios (DGFPS) de España y el laboratorio Zervier anunciaron la retirada del mercado de las especialidades Ponderal ${ }^{\circledR}$ y Dipondal ${ }^{\circledR}$. Los fármacos que contienen son, respectivamente, fenfluramina y dexfenfluramina, dos anorexígenos que han sido ampliamente utilizados en todo el mundo - sobre todo en Europa- para el tratamiento de la obesidad. La decisión estuvo motivada por el riesgo de que estos fármacos puedan inducir graves lesiones valvulares cardíacas.

Desde hace tiempo se sabe que los anorexígenos pueden producir hipertensión pulmonar primaria. Durante los años sesenta se había descrito que uno de estos fármacos, el aminorex, había causado una serie de casos de esta grave enfermedad en Alemania, Austria y Suiza. Desde la comercialización de la fenfluramina y la dexfenfluramina se han descrito diversos casos de hipertensión pulmonar primaria asociados con el uso de estos fármacos, y más recientemente un estudio de casos y controles mostró que los pacientes que habían tomado uno de los anorexígenos derivados de la fenfluramina presentaban un riesgo 6,3 veces superior de hipertensión pulmonar primaria respecto de los que no lo habían tomado. Este riesgo llegaba a ser 23 veces mayor si los fármacos se habían tomado durante 3 meses o más. Al suspender su administración el riesgo disminuía.

A raíz de esos resultados el Comité de Especialidades Farmacéuticas de la Unión Europea (CPMP) hizo públicas unas recomendaciones para restringir el uso de todos los anorexígenos de acción central. El CPMP hizo notar que su uso solo se considera indicado en caso de obesidad marcada, es decir, con un índice de masa corporal de 30 que no haya respondido a una dieta de adelgazamiento adecuada. Además, advertía que se debe tener en cuenta que un tratamiento largo se asocia con un riesgo más elevado de hipertensión pulmonar y que médicos y pacientes deben conocer este riesgo. En Canadá y Estados Unidos se tomaron medidas similares.

\section{ENMIENDAS A LA ROTULACIÓN}

\section{Datos pediátricos: se exige la rotulación de los nuevos medicamentos (Estados Unidos de América)}

La Administración de Alimentos y Medicamentos (FDA) ha propuesto nuevos reglamentos que exigen la realización de estudios pediátricos de ciertos nuevos medicamentos y productos biológicos. Muchos nuevos fármacos son, al menos a veces, el mejor tratamiento para los niños, pero en su mayoría no se han examinado debidamente en la subpoblación pediátrica.

Como resultado, en la etiqueta del producto se suelen omitir las indicaciones para el uso inocuo y eficaz en los niños. La regla propuesta exigirá que los fabricantes de una limitada clase de nuevos medicamentos y productos biológicos proporcionen, antes o poco después de la autorización, suficientes datos e información básica para corroborar las indicaciones para el uso pediátrico según los fines declarados. Los fabricantes de un número reducido de medicamentos y productos biológicos ya en venta también proporcionarían esos datos en circunstancias apremiantes.

Esa medida se ha tomado como parte de un esfuerzo exhaustivo por aumentar el número de medicamentos nuevos y de productos biológicos de importancia clínica para los niños, que lleven etiquetas apropiadas para uso en esos pacientes.

\section{Uso geriátrico: se agrega a la rotulación (Estados Unidos de América)}

La Administración de Alimentos y Medicamentos (FDA) ha enmendado el reglamento que determina el contenido y la presentación de las etiquetas de los productos farmacéuticos recetados para el ser humano, incluso de los productos biológicos, para dar información sobre el uso apropiado de los fármacos administrados a los ancianos y facilitar el acceso a esa información agregando a la etiqueta una subsección sobre "Uso geriátrico".

Esta enmienda se realizará dando prioridad a ciertas clases de medicamentos por causa de las alteraciones fisiológicas que sufre el paciente con la edad, el reducido espectro terapéutico de algunos fármacos y el potencial de interacción de un producto con otro y con la enfermedad, así como otros factores. La FDA ha seleccionado las siguientes clases de fármacos o productos medicamentosos para enmienda a la rotulación por orden de prioridad:
- psicotrópicos
- antidepresivos
- calmantes
- hipnóticos
- antipsicóticos
- antiinflamatorios no esteroides (AINE)
- digoxina
- antiarrítmicos - bloqueadores de los canales de
calcio 
- hipoglucémicos de administración oral

- anticoagulantes

- quinolonas.

Puede solicitarse el texto completo.

\section{Lamotrigina: advertencia por causa de reacciones cutáneas graves (Australia)}

El Comité de Evaluación de Reacciones Medicamentosas Adversas ha recomendado que se incluya una advertencia enmarcada en la etiqueta de lamotrigina (Lamictal ${ }^{\circledR}$ : Glaxo Wellcome), producto anticonvulsivo, a efectos de que se han notificado erupciones graves potencialmente mortales por el uso de este producto, especialmente en los niños. Por lo tanto, se debe descontinuar la lamotrigina al primer signo de erupción, a no ser que se compruebe que no guarda relación alguna con el medicamento.

\section{Terfenadina y terfenadina/pseudoefedrina: advertencia sobre interacciones (Estados Unidos de América)}

Los fabricantes del antihistamínico terfenadina y de la combinación de antihistamínico y descongestionante que contiene terfenadina y pseudoefedrina $\quad\left(\right.$ Seldane ${ }^{\circledR}$ y Seldane-D ${ }^{\circledR}$ : Hoechst Marion Roussel) han agregado nuevas advertencias en la etiqueta del producto.

Por mucho tiempo se ha sabido que los productos a base de terfenadina acarrean graves riesgos cuando se toman con ciertos antibióticos y antimicóticos. La nueva etiqueta ofrece información sobre una nueva contraindicación del uso de terfenadina y terfenadina/pseudoefedrina con mibefradil, el antihipertensivo cuya venta se ha autorizado recientemente.

Entre las advertencias también se ha indicado que no se debe tomar terfenadina con ninguno de los diversos medicamentos de uso recientemente autorizado, entre ellos los siguientes:
- inhibidores de la proteasa del VIH, como indinavir, ritonavir, saquinavir y nelfinavir,

- antagonistas de la serotonina, como fluvoxamina, sertralina y nefazodona

- zileutón

- cisaprida

- esparfloxacina.

Además, en la nueva etiqueta se especifica que los pacientes con trastornos renales no deben tomar más de una tableta diaria de terfenadina ni de terfenadina/pseudoefedrina y que la terfenadina no debe tomarse con jugo de toronja.

La Administración de Alimentos y Medicamentos (FDA) ha propuesto retirar del mercado los productos a base de terfenadina porque ahora se vende fexofenadina, un sucedáneo más inocuo. Las nuevas advertencias tienen por fin dar la última información sobre riesgos a los dispensadores de atención de salud y a los consumidores que todavía usen esos productos.

\section{Difenhidramina: advertencias (Estados Unidos de América)}

La Administración de Alimentos y Medicamentos (FDA) ha propuesto enmendar la versión preliminar de la monografía final de los productos a base de difenhidramina de venta libre para uso tópico como analgésicos externos y fármacos de administración oral empleados como antieméticos, antihistamínicos, antitusivos y soporíferos. La enmienda agrega advertencias sobre la toxicidad de la difenhidramina y aconseja a los pacientes que se abstengan de:

- usar productos de venta libre que contengan difenhidramina para tratar la varicela, la urticaria causada por hiedra venenosa, las quemaduras solares, extensas partes del cuerpo, piel ampollada o supurada, con frecuencia mayor de la recomendado, o con cualquier otro producto a base de difenhidramina, aunque sea de administración oral;

- usar productos de venta libre de administración oral a base de difen- hidramina con cualquier otro producto a base de difenhidramina, incluso los de uso tópico.

\section{Enmiendas a la rotulación del analgésico Duract ${ }^{\circledR}$ para incluir advertencia (EUA)}

La Administración de Alimentos y Medicamentos (FDA) y los WyethAyerst Laboratories han informado a los médicos sobre una nueva advertencia enmarcada en la etiqueta de Duract $^{\circledR}$ (cápsulas de bromfenaco sódico), un tratamiento breve para aliviar el dolor. El uso de este producto por más de 10 días puede causar lesiones hepáticas graves. Los pacientes tratados por más de 10 días han tenido manifestaciones de ictericia, hepatitis fulminante e insuficiencia hepática que exige transplante.

Este producto está recomendado específicamente para el tratamiento del dolor agudo por un período breve (10 días o menos) y la etiqueta no indica que deba usarse por un tiempo prolongado para afecciones crónicas, como osteoartritis o artritis reumatoide.

En una circular enviada a los médicos por el fabricante, la Wyeth-Ayerst de Filadelfia, Pensilvania, se les advierte sobre casos de hepatitis grave e insuficiencia hepática (que en algunos casos exige transplante) en pacientes tratados con Duract ${ }^{\circledR}$ por más de un mes sin observación de las enzimas hepáticas. Aunque hasta la fecha han ocurrido pocos traumatismos de esa índole, se desconoce la incidencia real del problema.

La FDA aconseja a los médicos que estimen necesario emplear Duract ${ }^{\circledR}$ por más de 10 días que observen estrictamente al paciente para determinar si tiene problemas hepáticos.

Con objeto de proporcionar más información sobre el uso inocuo de esos medicamentos, la FDA ha pedido que el fabricante agregue una advertencia enmarcada en la etiqueta donde se indiquen los riesgos a los médicos y se recalque que se recomienda emplear el fármaco 10 días o menos. En la nueva información sobre la rotulación se recomienda aconsejar a los pacien- 
tes que tomen Duract ${ }^{\circledR}$ estrictamente de la forma indicada. Se ha actualizado la advertencia en la etiqueta del producto para incluir la hepatotoxicidad grave observada.

\section{Dispositivos a base de látex: se exige rotulación (Estados Unidos de América)}

Como resultado de varios informes de reacciones alérgicas a algunos dispositivos médicos, la Administración de Alimentos y Medicamentos (FDA) exige que todos los dispositivos médicos que contengan látex se rotulen como tales y lleven una advertencia de que el látex puede causar reacciones alérgicas.

Se exigirá la siguiente declaración en la etiqueta y el envase de los dispositivos que contengan látex de caucho natural: "Atención: Este producto contiene látex de caucho natural que puede causar reacciones alérgicas". Los productos y el envase que contengan caucho natural seco deberán identificarse como tales.

En el último decenio, la FDA ha recibido más de 1700 informes de reacciones alérgicas graves, incluso de 16 defunciones, causadas por dispositivos médicos que contienen látex. Todas las defunciones ocurrieron en 1989 en niños con espina bífida y fueron causadas por una reacción a las boquillas de látex empleadas en la punta de los catéteres del enema de bario. El fabricante retiró voluntariamente del mercado las boquillas del enema de bario y comenzó a usar boquillas de silicona.

Se han notificado reacciones alérgicas a una amplia gama de dispositivos médicos que contienen látex, incluso a guantes quirúrgicos de látex, curitas adhesivas, catéteres intravenosos y equipos de anestesia. Hay dos grupos que corren un riesgo mayor que el del público en general por la exposición constante al látex: los trabajadores de salud y los niños con espina bífida y otras afecciones que exijan varios procedimientos quirúrgicos.

La FDA también exige que se supriman las declaraciones de que los dispositivos médicos son "hipoalérge- nos" porque ello implica incorrectamente que pueden ser empleados con seguridad por personas sensibles al látex. Esas declaraciones se encuentran ahora en muchos dispositivos médicos que contienen una baja concentración de proteína de látex. Sin embargo, esos productos pueden causar reacciones alérgicas en personas sensibles al látex.

\section{Condones de látex: fecha de vencimiento (Estados Unidos de América)}

La Administración de Alimentos y Medicamentos (FDA) ha introducido un reglamento final que exige que en la etiqueta de los condones de látex se indique la fecha de vencimiento a partir de las pruebas físicas y mecánicas realizadas después de exponer el producto a diferentes condiciones que deterioran el látex, indicación que deberá hacerse en la envoltura externa y en cada paquete.

Varios estudios muestran que los condones de látex se deterioran con el tiempo. Esa degradación tiene un importante efecto en la capacidad del producto para proporcionar una barrera contra los agentes de enfermedades de transmisión sexual, incluso contra el virus de la inmunodeficiencia humana (VIH).

Ese organismo también ha determinado que si un condón de látex contiene espermicida y la fecha de vencimiento basada en pruebas de la estabilidad del espermicida es diferente de la basada en pruebas de la integridad del látex, el producto deberá llevar solamente la fecha de vencimiento más temprana.

\section{REACCIONES ADVERSAS}

\section{Inhibidores de la proteasa de VIH: hiperglucemia (Reino Unido)}

El Comité de Inocuidad de los Medicamentos ha recibido ahora informes de más de 100 casos de hiperglucemia en pacientes tratados con los inhibidores de la proteasa de VIH indina$\operatorname{vir}\left(\right.$ Crixivan $\left.{ }^{\circledR}\right)$, ritonavir $\left(\right.$ Norvir $\left.^{\circledR}\right)$ y saquinavir (Invirase ${ }^{\circledR}$ ). Algunos pacientes tratados con estos productos necesitaron hospitalización para el tratamiento de cetoacidosis; otros, la administración inicial o el ajuste de la dosis de insulina o de agentes hipoglucemiantes orales; y otros presentaron hiperglucemia continua después de haberse suspendido el medicamento.

Algunos pacientes tenían afecciones médicas que necesitaban tratamiento con otros fármacos por causa de manifestaciones de hiperglucemia. Sin embargo, los médicos y farmacéuticos deben saber que esas reacciones pueden ocurrir en pacientes tratados con inhibidores de la proteasa de VIH.

\section{Paracetamol: medidas restrictivas (Irlanda)}

Después de un examen de los productos a base de paracetamol, la Junta Irlandesa de Medicamentos ha analizado las condiciones que rigen la venta de paracetamol por causa del riesgo de lesión hepática irreversible después de una dosis excesiva.

La declaración "Contiene paracetamol" se imprimirá en un lugar claramente visible de la caja del envase junto con la siguiente advertencia: “No tome ningún otro producto que contenga paracetamol".

La etiqueta del envase contendrá además la siguiente advertencia: "Debe buscar atención médica inmediata si toma una dosis excesiva aunque se sienta bien. Sírvase leer el prospecto adjunto con cuidado".

El prospecto del envase debe llevar la siguiente declaración: "Debe buscar atención médica inmediata si toma una dosis excesiva por el riesgo de lesión hepática irreversible".

Todas las tabletas de paracetamol de venta libre deben empacarse en envases burbuja o en unidades de dosificación comparables envueltas individualmente y con protección para niños. El tamaño máximo del paquete de productos a base de paracetamol de venta libre en las farmacias se limitará a un total de 24 tabletas (500 mg) o a la cantidad equivalente de paracetamol y $140 \mathrm{~mL}$ de formulaciones pediátri- 
cas $(120 \mathrm{mg} / 5 \mathrm{~mL})$ o de formulaciones para niños un poco mayores (junior) (250 mg/5 mL), o su equivalente. El suministro de más de un paquete a un solo paciente debe realizarse bajo la supervisión y discreción del farmacéutico. Se exigirá receta para despachar más de 50 tabletas.

En casos de urgencia se venderán preparaciones cuyo único ingrediente sea el paracetamol solo en establecimientos distintos de las farmacias con las siguientes restricciones:

- El tamaño máximo del paquete de paracetamol se limitará a un total de 12 tabletas $(500 \mathrm{mg}$ ) o a la cantidad equivalente, envasada en paquetes de una sola dosis para uso por adultos y de $60 \mathrm{~mL}(120 \mathrm{mg} / 5 \mathrm{~mL})$ para formulaciones pediátricas líquidas. Se debe suministrar solo un paquete a la vez.

Estos nuevos requisitos han entrado en vigor para todas las nuevas preparaciones de paracetamol y el 30 de septiembre de 1997 para los productos existentes.

\section{Cloruro de suxametonio: advertencia de paro cardíaco e hipercaliemia (Estados Unidos de América)}

El fabricante del agente bloqueador neuromuscular cloruro de suxametonio (succinilcolina, Sucostrin ${ }^{\circledR}$ : Bristol-Myers Squibb) ha señalado dos trastornos potencialmente mortales causados por su uso:

- Paro cardíaco en niños y adolescentes. Se han recibido varios informes de paro cardíaco después de la administración de cloruro de suxametonio a niños y adolescentes aparentemente sanos, a quienes luego se les descubrió miopatía sin diagnosticar. Conviene usar un bloqueador neuromuscular no polarizante para la cirugía electiva de rutina de esos pacientes.

- Hipercaliemia. Excepto cuando se usa para intubación traqueal de emergencia o en casos en que se ne- cesita proteger inmediatamente una vía respiratoria, el cloruro de suxametonio está contraindicado para pacientes después de la fase aguda de una lesión sufrida a raíz de quemaduras graves, traumatismo múltiple, extensa desnervación del músculo esquelético, o lesión de las neuronas motoras superiores porque la administración a esas personas puede causar hipercaliemia grave, conducente a paro cardíaco. El riesgo de hipercaliemia en esos pacientes aumenta con el tiempo y suele ser máximo de 7 a 10 días después de la lesión, según su gravedad y localización. Se desconoce el tiempo preciso del comienzo y de la duración del período de riesgo.

\section{Ácido alendrónico: esofagitis (Australia)}

En el primer semestre de 1997, el Comité de Reacciones Adversas a los Medicamentos recibió 67 informes de presuntas reacciones adversas al uso de ácido alendrónico (58 mujeres y nueve hombres), un bifosfonato recomendado para el tratamiento de la osteoporosis en mujeres posmenopáusicas y la enfermedad ósea de Paget. Los casos con síntomas gastrointestinales o musculoesqueléticos representaron $75 \%$ de los informes.

De particular importancia son 22 informes en los que se documentó el comienzo temprano de varios problemas esofágicos (en su mayoría, la primera semana). Tres de esos informes fueron acompañados de los resultados de endoscopia que mostraban ulceración esofágica grave. Tres informes indicaron problemas esofágicos a pesar de haber observado las contraindicaciones y precauciones especificadas en la información sobre el producto.

Los prescriptores deben saber que el ácido alendrónico puede causar esofagitis grave y difundida que puede lesionar el esófago en toda su extensión. Entre las precauciones específicas que deben observarse están tomar el medicamento con un vaso lleno de agua solamente después de levantarse por la mañana; los pacientes no deben acos- tarse al menos por 30 minutos después de tomar la dosis ni hasta después de tomar la primera comida del día.

\section{Ginecomastia provocada por medicamentos: análisis de informes (Australia)}

Desde noviembre de 1972, el Comité de Reacciones Adversas a los Medicamentos ha recibido 332 informes de presuntos casos de ginecomastia provocada por medicamentos en pacientes cuya edad varió de 8 a 91 años (edad mediana de 62). En muchos casos, en un principio no se sospechó que hubiera ninguna causa medicamentosa y el tratamiento continuó por varias semanas o meses después del comienzo del trastorno. Cuatro informes se complementaron con los resultados de una biopsia por excisión que confirmaron que no había tumores malignos. Los medicamentos más comúnmente notificados (que representaron más de $75 \%$ del total) se enumeran a continuación (10 informes o más):

$\begin{array}{lc}\text { Medicamento } & \begin{array}{r}\text { No. de informes } \\ \text { (único fármaco } \\ \text { sospechado) }\end{array} \\ \text { Espironolactona } & 77(62) \\ \text { Cimetidina } & 49(39) \\ \text { Ranitidina } & 32(25) \\ \text { Digoxina } & 22(7) \\ \text { Simvastatina } & 19(11) \\ \text { Verapamilo } & 14(7) \\ \text { Furosemida } & 13(0) \\ \text { Ácido acetilsalicílico } & 12(0) \\ \text { Famotidina } & 11(6) \\ \text { Omeprazol } & 10(8)\end{array}$

Los medicamentos antiulcerosos (cimetidina, ranitidina, famotidina, y omeprazol) representan 30\% del total.

La ginecomastia provocada por medicamentos suele ser bilateral, pero a menudo es asimétrica y se estima que su manifestación está relacionada con la dosis diaria y la duración del tratamiento. Por lo general, es reversible después de suspender el medicamento, aunque la recuperación total puede tardar varios meses. Esta afección es dolorosa a menudo y puede 
causar preocupación por un posible tumor maligno. Antes de practicar una cirugía es preciso descartar la posibilidad de una causa medicamentosa.

\section{Metotrexato (en dosis bajas): discrasias sanguíneas y otras reacciones adversas (Reino Unido)}

El Comité de Inocuidad de los Medicamentos ha alertado a los prescriptores con respecto a informes de discrasias sanguíneas y otras reacciones adversas relacionadas con el uso de metotrexato en dosis bajas. El metotrexato es un antimetabolito empleado a dosis altas para tratar las neoplasias y en dosis bajas para tratar la psoriasis y la artritis reumatoide.

Se sabe que al administrarlo en dosis altas causa discrasias sanguíneas graves y a veces mortales $y$, con menor frecuencia, hepatitis, cirrosis y fibrosis pulmonar. El Comité ha recibido 83 informes de discrasias sanguíneas, 36 con resultados mortales, en pacientes tratados con metotrexato a dosis bajas. En muchos de esos casos, hubo factores que pudieron haber aumentado la toxicidad del metotrexato, incluso la edad avanzada, la deficiencia de la función renal y la interacción con medicamentos con propiedades antifolato (por ejemplo, la combinación de trimetoprima y sulfametoxazol). Se han recibido otros cuatro informes de cirrosis hepática relacionada con un tratamiento con metotrexato a dosis bajas para la psoriasis o la artritis reumatoide.

El Comité recalca que los pacientes tratados con metotrexato a dosis bajas deben hacer lo siguiente:

- Someterse a un hemograma completo y a análisis de la función renal y hepática antes de comenzar el tratamiento. Esos exámenes deben repetirse semanalmente hasta que se estabilice el tratamiento y, de ahí en adelante, es preciso vigilar a los pacientes cada 2 ó 3 meses durante todo el tratamiento.

- Notificar todos los síntomas y signos que indiquen infección, especialmente el dolor de garganta.
Si ocurre toxicidad aguda por el metotrexato, quizá haya que tratar a los pacientes con ácido folínico.

\section{Cambios terapéuticos: se piden datos para evaluar los riesgos (Estados Unidos de América)}

La Administración de Alimentos y Medicamentos (FDA) ha pedido informes a los profesionales de atención de salud sobre cualquier consecuencia adversa de los "cambios terapéuticos", es decir, el empleo de un fármaco totalmente diferente en sustitución de uno recetado. En algunos planes de atención de salud prepagada y de otra índole se hacen con frecuencia cada vez mayor esas sustituciones, particularmente en los servicios ambulatorios, para administrar el presupuesto para productos farmacéuticos.

La FDA ha recibido varios informes de efectos adversos aparentemente causados por los cambios terapéuticos. Aunque los fármacos pertenecientes a una clase terapéutica pueden tener perfiles similares de eficacia e inocuidad, una vez que se gradúa la entidad molecular administrada a un paciente, el cambio a otra podría causar un efecto adverso si la nueva graduación no tiene efecto óptimo. Además, un paciente puede sufrir diferentes efectos adversos e interacciones medicamentosas con productos de la misma clase farmacológica. Los efectos de los cambios terapéuticos no suelen estudiarse durante el proceso de preparación de nuevos medicamentos. La FDA está investigando si los riesgos del caso pueden estimarse por medio de vigilancia poscomercialización.

\section{Nueva información importante sobre la inocuidad del Hismanal ${ }^{\circledR}$ (Estados Unidos de América)}

La FDA ha advertido a los consumidores y proveedores de atención de salud que hay nueva información sobre la inocuidad del Hismanal ${ }^{\circledR}$ (astemizol), antihistamínico recetado. Esa advertencia se ha hecho por ha- berse agregado a la etiqueta del producto más información sobre sus efectos cardiovasculares adversos, nuevas clases de interacción potencialmente grave con otros medicamentos e informes raros de anafilaxis, reacción que puede ser mortal.

El Hismanal ${ }^{\circledR}$ acarrea el riesgo de muerte por arritmia cardíaca cuando se toma con otros fármacos y se emplea en una dosis mayor que la recomendada en la etiqueta. La nueva etiqueta contiene información sobre una advertencia específica contra el uso simultáneo de Hismanal ${ }^{\circledR}$ con otros tipos de medicamentos, tales como Posicor $^{\circledR}$ (dihidrocloruro de mibefradil), producto antihipertensivo, y los antibióticos Biaxin ${ }^{\circledR}$ (claritromicina) y $\mathrm{TAO}^{\circledR}$ (toleandomicina).

La nueva rotulación también contiene otras advertencias sobre el uso de Hismanal ${ }^{\circledR}$ con varios otros fármacos. Entre ellos cabe citar los inhibidores de la proteasa de VIH, como Crixi$\operatorname{van}^{\circledR}$ (indinavir), Norvir ${ }^{\circledR}$ (ritonavir), Invirase ${ }^{\circledR}$ (saquinavir) y Viracept ${ }^{\circledR}$ (elinavir), los inhibidores de la reabsorción de la serotonina, como Prozac ${ }^{\circledR}$ (fluoxetina), Luvox ${ }^{\circledR}$ (fluvoxamina), Zoloft $^{\circledR}$ (sertralina), Serzone ${ }^{\circledR}$ (nefazodona) y Paxil ${ }^{\circledR}$ (paroxetina) y Zyflo ${ }^{\circledR}$ (zileutón), un antiasmático. Además, en la etiqueta se recomienda ahora que no se debe tomar Hismanal ${ }^{\circledR}$ con jugo de toronja. Dichas recomendaciones se basan en la posibilidad de que esos medicamentos y el jugo de toronja obstaculicen la forma en que el cuerpo absorbe y metaboliza el Hismanal ${ }^{\circledR}$.

En la nueva etiqueta también se recalca que los pacientes con afecciones hepáticas no deben tomar Hismanal ${ }^{\circledR}$. La nueva etiqueta tiene por fin dar la última información disponible sobre esos riesgos a los dispensadores y consumidores de atención de salud que usen Hismanal ${ }^{\circledR}$.

\section{Jalea real: advertencia sobre reacciones alérgicas graves (Australia, Nueva Zelandia)}

La Administración de Productos Terapéuticos y la Administración de 
Alimentos de Australia y Nueva Zelandia examinarán de nuevo la inocuidad de los productos que contienen jalea real por la continua atribución de reacciones alérgicas graves a ese producto. La jalea real es una secreción rica en proteína de las glándulas salivales de las abejas obreras que se da a las larvas de las futuras reinas. Se usa mucho como tónico para la salud en los sistemas de medicina alternativa.

De momento, los envases de productos de jalea real, incluso los que están actualmente en el mercado, deben llevar una enérgica advertencia impresa en un espacio de por lo menos $3 \mathrm{~mm}$ de alto, que diga lo siguiente: "Este producto contiene jalea real que, según se informa, causa reacciones alérgicas graves $\mathrm{y}$, en casos raros, la muerte, sobre todo a pacientes de asma y alergia".

\section{Somatropina (recombinante): advertencia sobre la abstención del uso en casos de catabolismo agudo (Estados Unidos de América)}

El fabricante ha informado a los médicos de los resultados de dos estudios sobre el uso de somatropina recombinante (Genotropin ${ }^{\circledR}$ : Pharmacia \& Upjohn) para el tratamiento del catabolismo agudo en pacientes gravemente enfermos y recomendado que se interrumpa de inmediato el uso de ese producto para dicha indicación, incluso para el tratamiento pre y postoperatorio de pacientes gravemente enfermos y quemados.

Los resultados de ambos estudios muestran una tasa de mortalidad mucho mayor en los pacientes tratados con somatropina que en quienes recibieron un placebo o no se trataron. Se incluyó un total de 532 pacientes en los dos estudios; 259 fueron tratados con somatropina, 264 recibieron placebo y 9 se dejaron sin tratar. La tasa de mortalidad conjunta de los pacientes tratados con placebo $(48 / 264)$ fue de $18,2 \%$ y de los tratados con somatropina $(108 / 259)$, de $41,7 \%$. Se han sometido los datos a un análisis más detallado para entender claramente las razones de esas diferencias.
El fabricante recalca que esta recomendación no se aplica al uso de la somatropina recombinante para el tratamiento de los niños con retraso del crecimiento por secreción insuficiente de la hormona endógena del crecimiento.

\section{Terbinafina: riesgo de reacciones cutáneas graves (Alemania)}

La Comisión de Medicamentos de la Profesión Médica Alemana ha expresado preocupación porque a menudo se recalca la eficacia del tratamiento antimicótico, especialmente del administrado por vía oral, sin destacar lo suficiente las reacciones adversas. Varios agentes antimicóticos han suscitado inquietud por las reacciones adversas que causan en el hígado y el sistema hemático y por su interacción con otros fármacos. La terbinafina, agente antimicótico relativamente nuevo del grupo de las alilaminas, causa reacciones aun más adversas, incluso alteración del gusto.

Según informes recibidos de la Comisión, las observaciones de reacciones cutáneas representan alrededor de $30 \%$ de los informes de reacciones adversas causadas por terbinafina, incluso eritema exudativo multiforme y presuntos casos aislados del síndrome de Stevens-Johnson y necrólisis epidérmica tóxica.

Las reacciones cutáneas graves se registran en el Centro de Documentación de Reacciones Cutáneas Graves en Friburgo. Desde que se introdujo la terbinafina, el Centro ha registrado cuatro casos de reacciones cutáneas graves, incluso dos casos del síndrome de Stevens-Johnson y dos casos de este mismo síndrome que se convirtieron en necrólisis epidérmica tóxica. Las reacciones graves de la piel ocasionan una mayor tasa de mortalidad, de cerca de $6 \%$ por el síndrome de Stevens-Johnson, de $25 \%$ por la forma de transición de dicho síndrome a necrólisis epidérmica tóxica y de más de $40 \%$ por la forma máxima de necrólisis epidérmica tóxica (síndrome de Lyell).
Por ende, la Comisión recomienda que se considere la posibilidad de administrar el tratamiento tópico primero cuando haya onicomicosis y que se mantenga una limitada escala de indicaciones para el tratamiento con terbinafina oral a partir de un amplio y minucioso análisis de riesgos contra beneficios

\section{Aviso de salud pública de la FDA sobre posibles reacciones de hipersensibilidad a los dispositivos médicos impregnados de clorhexidina (Estados Unidos de América)}

La FDA ha informado sobre la posibilidad de graves reacciones de hipersensibilidad a los dispositivos médicos impregnados de clorhexidina. Como los usuarios de los dispositivos no conocen bien esas clases de reacciones y aún no está claro cuán grave es el problema, dicho organismo ha suministrado la información obtenida hasta la fecha y pedido que se notifiquen esas reacciones de hipersensibilidad a medida que ocurran. Eso ayudará a evaluar el peligro que podrían acarrear esos productos para la salud pública y a determinar qué medidas se deben tomar, si es del caso.

\section{Amiodarona: graves trastornos pulmonares (Alemania)}

La Comisión de Medicamentos de la Profesión Médica Alemana recibió varios informes de trastornos pulmonares relacionados con el uso de amiodarona, antiarrítmico de la clase III, incluso neumonitis intersticial crónica, neumonía con bronquiolitis obliterante, síndrome de dificultad respiratoria aguda (con frecuencia después de procedimientos quirúrgicos o angiográficos en la cavidad torácica) y focos pulmonares solitarios (presuntos tumores). La amiodarona es actualmente el único otro medicamento disponible de esta clase, fuera del sotalol. 
Según estudios recientes, se observan neumopatías en $5,8 \%$ de los pacientes tratados si la dosis de sostén diaria pasa de $300 \mathrm{mg}$. Por ende, se deben escoger como meta dosis diarias de 200 a $300 \mathrm{mg}$ porque la administración de más de $300 \mathrm{mg}$ aumenta la incidencia de esas reacciones medicamentosas adversas peligrosas y potencialmente mortales. La Comisión pide a todos los profesionales de la salud que sigan notificando cualquier observación correspondiente, incluso los casos sospechados.

\section{DECISIONES DIVERSAS}

\section{Pseudoefedrina, fenilpropanolamina y efedrina: se propone su clasificación (Estados Unidos de América)}

La Administración para la Ejecución de las Leyes sobre Estupefacientes (DEA) ha propuesto la regulación de la pseudoefedrina, la fenilpropanolamina y los compuestos farmacéuticos de efedrina como productos de la Lista I de la Ley General sobre Fiscalización de la Metanfetamina promulgada en 1996, que incluye la notificación de ciertas transacciones relacionadas con esos compuestos.

Esta medida somete a los distribuidores de esos productos al requisito del registro. Además, la distribución, importación y exportación de los productos se sometería a la fiscalización vigente de las sustancias químicas en lo que respecta a transacciones reglamentadas, excepto en determinadas circunstancias. La Ley también exige que el Servicio Postal o las empresas transportadoras privadas o comerciales presenten informes sobre ciertas clases de distribución de esos productos a personas no sujetas a reglamentación.

Tales medidas se han tomado para combatir el tráfico ilícito de esas sustancias, compradas en grandes cantidades y empleadas para producir metanfetamina en laboratorios clandestinos. Los traficantes han aprovechado una rendija en la legislación anterior, que eximía de control a la compra de efedrina como producto farmacéutico.

Ahora las exenciones se aplican a las ventas de productos ordinarios de pseudoefedrina y fenilpropanolamina sin receta por distribuidores minoristas; el volumen de venta mínimo de esos productos por un distribuidor minorista se ha fijado en 24 gramos en una sola transacción. Los productos ordinarios de pseudoefedrina y fenilpropanolamina de venta libre se definen como un producto envasado que no contenga más de 3 gramos de base de pseudoefedrina o de fenilpropanolamina por paquete, fabricado en envase burbuja, con dos unidades de dosificación por burbuja como máximo o, donde el uso de envases burbuja no sea técnicamente factible, fabricado en empaques o bolsas de una unidad de dosificación. El producto líquido se vende en empaques que no contienen más de 3 gramos de base de pseudoefedrina o fenilpropanolamina.

\section{Decisión sobre el uso de fluorocarburos clorados: revisión (Suiza)}

La Oficina Intercantonal de Fiscalización de Medicamentos ha examinado la decisión relativa al uso de fluorocarburos clorados (CFC) en fármacos. No se deben usar más los CFC (halogenados total o parcialmente) en medicina humana ni veterinaria. Sin embargo, los siguientes productos están eximidos hasta cuando se consigan sustitutos:

- anticolinérgicos

- agonistas de los receptores $\beta$ adrenérgicos

- corticosteroides

- ácido cromoglícico y análogos.

En casos excepcionales, la Oficina puede permitir que se emplee una preparación para uso humano o veterinario con un fin médico particular, que contenga una nueva entidad química que sea un nuevo tratamiento o proce- dimiento de diagnóstico para el cual no haya otro propulsor apropiado.

En la rotulación de los medicamentos exentos se indicará el contenido de CFC y solo esos productos pueden comercializarse. Se ha concedido un período de transición hasta el 30 de junio de 1998 para los derivados del nitrato a base de CFC actualmente registrados.

\section{Sistemas de rayos láser con dímeros excitados: proceso judicial contra los dispositivos no autorizados (Estados Unidos de América)}

La Administración de Alimentos y Medicamentos (FDA) ha entablado un proceso judicial contra el uso no autorizado de rayos láser con dímeros excitados para tratar la miopía y otras afecciones oculares. Esa clase de rayos láser acarrea un riesgo para los pacientes porque podrían causar graves traumatismos oculares. La FDA también insta encarecidamente a los pacientes a asegurarse de que la cirugía se practique solo con rayos láser autorizados o en un estudio clínico supervisado por la FDA.

En los últimos 3 años, la FDA ha enviado 24 cartas de advertencia a los fabricantes y médicos sobre la venta y el uso no autorizado de rayos láser con dímeros excitados y hace poco comenzó a decomisar los sistemas de rayos láser de un fabricante determinado en tres clínicas de oftalmología por no haber hecho caso de las advertencias. Las investigaciones siguen y la FDA se propone intensificar las medidas de ejecución de la ley.

En la actualidad, la FDA ha autorizado el uso de solo dos clases de rayos láser para cirugía ocular refractiva, fabricados por las compañías Summit Technology y VISX. Ambas empresas realizaron ensayos clínicos para demostrar que sus rayos láser permitían tratar la miopía de una forma inocua y eficaz, con un procedimiento llamado queratectomía fotorrefringente. En la actualidad, se someten a ensayo varios otros rayos láser con dímeros excitados en estudios clínicos sancionados por la FDA. 


\section{Estuches de pruebas detectoras de antígenos de estreptococos del grupo B: diagnóstico equivocado potencialmente mortal (Estados Unidos de América)}

La Administración de Alimentos y Medicamentos (FDA) ha alertado a los profesionales de la salud con respecto al diagnóstico equivocado, que puede ser mortal, cuando se usan estuches de pruebas detectoras de antígenos de estreptococos del grupo B y ofrece pautas sobre la forma de usar esos análisis debidamente. Las pruebas detectoras de antígenos de estreptococos del grupo B han dado resultados negativos falsos en especímenes tomados de mujeres embarazadas y lactantes que murieron posteriormente de enfermedad estreptocócica del grupo B.

Los análisis también han producido resultados positivos falsos que pueden llevar a la administración de un tratamiento inapropiado con antibióticos y a una larga hospitalización. Los médicos deben entender las limitaciones de esos dispositivos. Las pruebas detectoras de antígenos son un suplemento al diagnóstico y no son un buen sustituto del cultivo bacteriano debidamente realizado para el diagnóstico de la enfermedad estreptocócica del grupo B.

\section{Estuches de prueba de uso domiciliario: advertencia (Estados Unidos de América)}

La Administración de Alimentos y Medicamentos (FDA) ha puesto a los consumidores sobre alerta con respecto a dos estuches para pruebas domiciliarias que no han sido autorizados y que se venden fraudulentamente. Uno se anuncia en la Internet, con el nombre de The Lei-Home Access HIV Test, como un estuche de uso personal para efectuar la prueba detectora del VIH. El otro se llama In-home Hepatititis A Test Kit. Ambos son distribuidos por LeiHome Access Care, división de la compañía Jin-Greene Biotechnology, Inc.
Los resultados de cualquier prueba de uso domiciliario no autorizada son poco fidedignos. La FDA recomienda que los farmacéuticos retiren esos estuches de pruebas no autorizados de los estantes de sus almacenes.

En la actualidad, el único sistema de recolección de pruebas del VIH de uso domiciliario autorizado en los Estados Unidos es el Home Access HIV-1 Test System (llamado también Home Access Express HIV-1 Test System) fabricado por la Home Access Health Corporation. El que dispone de este sistema en su casa envía una muestra de sangre seca obtenida por punción digital a un laboratorio de análisis. Con esta prueba se pueden obtener resultados confidenciales muy precisos por teléfono y hay un orientador experto para quienes lo necesiten. La FDA no ha autorizado el uso de estuches para pruebas de uso domiciliario para la hepatitis A.

\section{Soluciones inhaladas: se exige esterilidad (Estados Unidos de América)}

La Administración de Alimentos y Medicamentos (FDA) ha propuesto que se exija la esterilidad de todas las soluciones de nebulización inhaladas. En la actualidad, alrededor de la mitad se fabrican como productos estériles. Según los informes de efectos adversos a los medicamentos debido al empleo de soluciones de nebulización inhaladas no estériles contaminadas y del retiro del mercado de esos productos, la FDA ha tomado esa medida para asegurarse de la inocuidad y eficacia de esas soluciones.

\section{Rifabutina: enmienda de las indicaciones e interacciones (Reino Unido)}

El Comité de Inocuidad de los Medicamentos señala que, a la luz de las pautas publicadas y de un análisis más detallado de los principales ensayos hechos, se ha enmendado la informa- ción sobre la rifabutina. Este producto se recomienda ahora para lo siguiente:

- La profilaxis de la infección causada por el complejo Mycobacterium avium intracellulare (CMA) solamente en pacientes infectados por el VIH con un recuento de linfocitos CD4 inferior a 75 células por microlitro.

- El tratamiento de la enfermedad micobacteriana no tuberculosa (como la causada por el CMA y $M$. xenopi) o la tuberculosis pulmonar con regímenes combinados.

No se recomienda rifabutina para la profilaxis de la infección por el CMA en otros grupos de pacientes. El Comité también señala que la rifabutina activa la producción de enzimas hepáticas que suelen intervenir en el metabolismo de los medicamentos. Los siguientes son ejemplos de fármacos recetados con frecuencia cuyo metabolismo y eficacia pueden verse afectados por la rifabutina:

- anticonceptivos orales (se recomienda otro método de control de la natalidad);

- inhibidores de la proteasa del VIH (en particular ritonavir; se debe evitar el uso simultáneo);

- anticoagulantes;

- ciclosporina;

- hipoglucemiantes orales;

- anticonvulsivos, como fenitoína y carbamazepina.

Se ha producido uveítis con el tratamiento con rifabutina, sobre todo cuando se usa junto con la claritromicina. Se recomienda a los prescriptores que reduzcan la dosis de rifabutina a $300 \mathrm{mg}$ diarios cuando se use con antibióticos macrólidos o antimicóticos a base de triazol debido a las mayores concentraciones plasmáticas de rifabutina causadas por esa combinación. Esa reducción de la dosis de rifabutina, cuando se receta con claritromicina o fluconazol, ha disminuido la frecuencia de uveítis y permitido mantener una eficacia satisfactoria en el tratamiento de la infección por el CMA. 


\section{Aluminio en tabletas de acetato de calcio: se propone prueba para determinar el límite (Estados Unidos de América)}

La Farmacopea de los Estados Unidos de América ha propuesto que se realice una prueba del límite de aluminio para la monografía de las tabletas de acetato de calcio. Se recomienda tomar dos tabletas de $667 \mathrm{mg}$ de acetato de calcio por vía oral tres veces al día con las comidas para tratar la hiperfosfatemia en casos de insuficiencia renal terminal.

Los pacientes que deban someterse a diálisis o que tengan hiperfosfatemia pueden absorber aluminio sistemáticamente en proporción 10 veces mayor de lo normal, con efectos acumulativos. La exposición de los humores corporales a cantidades aun mínimas de aluminio, como puede suceder al consumir tabletas de acetato de calcio, podría causar efectos tóxicos para el sistema nervioso central a la larga. Según el límite propuesto, cada gramo de acetato de calcio debe contener $2 \mu \mathrm{g}$ de aluminio, como máximo.

\section{Talidomida: se autoriza} provisionalmente su empleo para tratar la lepra (Estados Unidos de América)

La Administración de Alimentos y Medicamentos (FDA) ha enviado a la compañía Celgene, Inc., una carta "de autorización provisional" del uso de talidomida para tratar una complicación de la lepra: las manifestaciones cutáneas del eritema nudoso leproso. Se trata de una afección grave para la cual no hay ningún otro tratamiento eficaz en la actualidad.

Dicho organismo ha determinado que, según los datos clínicos presentados, los beneficios de este producto son superiores a los riesgos conocidos para el tratamiento del eritema nudoso leproso cuando se usa con estricta supervisión médica. Sin embargo, antes de poder tomar una decisión final sobre la autorización, Celgene debe presentar más información, que incluya el texto de la etiqueta final y los detalles de un sistema de control de la distribución restringida, para escrutinio y aprobación por la FDA.

Con esta autorización provisional, la FDA está obrando de acuerdo con la autoridad que se le ha conferido para restringir la distribución de un producto cuya inocuidad es motivo de profunda preocupación. Esta carta aclara que si el producto llega a la etapa de autorización final en los Estados Unidos, estará sujeto a los requisitos de distribución limitada.

Es un hecho bien conocido que la talidomida causa graves defectos congénitos. Sin embargo, en los últimos años se ha aprendido mucho sobre su capacidad para modificar la respuesta del sistema inmunitario humano. Se ha avivado el interés de la comunidad de investigadores médicos en aprovechar ese efecto beneficioso de la talidomida a fin de fomentar su puesta a prueba para el tratamiento de enfermedades graves mediadas por el sistema immunitario, como el eritema nudoso leproso, para las cuales no existe ningún otro tratamiento eficaz en la actualidad.

\section{Esteroides anabólicos: control por medio de receta especial (Brasil)}

En vista del creciente uso indebido de los esteroides anabólicos, especialmente en los establecimientos de fisioculturismo, la Secretaría de Vigilancia Sanitaria del Ministerio de Salud ha decidido dispensar los siguientes compuestos, junto con sus sales, isómeros y precursores, con receta especial, copia de la cual deberá guardar el prescriptor:

- danazol

- fluoximesterona

- mesterolona

- nandrolona

- oximetolona

- testosterona.

\section{Butorfanol: clasificación propuesta (Estados Unidos de América)}

La Administración para la Ejecución de las Leyes sobre Estupefacientes ha propuesto que se clasifique el analgésico opioide butorfanol en la Lista IV de la Ley sobre Sustancias Fiscalizadas. La propuesta de dicho organismo se basa en una evaluación de los datos pertinentes, incluso en una evaluación científica y médica preparada por la Administración de Alimentos y Medicamentos (FDA). La recomendación incluye las sales e isómeros del butorfanol.

El butorfanol ha sido fuente de un creciente número de incidentes de abuso y desvío desde 1992. La Administración para la Ejecución de las Leyes sobre Estupefacientes ha recibido informes de todo el país que indican que el butorfanol se ha usado indebidamente y desviado por medio de recetas falsificadas y alteradas, recetas equivocadas y dispensación inapropiada, "compras por médicos" y solicitudes de repetición de la receta. A menudo se roba de las farmacias minoristas y de los hospitales. Además, el abuso del butorfanol intensifica el uso y el comportamiento tendiente a la toxicomanía.

\section{Antagonistas de los receptores $\mathrm{H}_{2}$ de la histamina de venta libre (Francia, Noruega)}

En Francia se venden ahora sin receta médica dos antagonistas de los receptores $\mathrm{H}_{2}$ de la histamina -famotidina (tabletas de $10 \mathrm{mg}$ ) y cimetidina (tabletas efervescentes de $200 \mathrm{mg}$ ) para el tratamiento sintomático breve del reflujo gastroesofágico en adultos.

La Autoridad de Fiscalización de Medicamentos de Noruega ha eximido del control por medio de receta a la famotidina (Pepcid ${ }^{\circledR}$ : Pharmacia \& Upjohn, $10 \mathrm{mg}$ ) y a la ranitidina (Zantac $^{\circledR}$ : Glaxo Wellcome, $75 \mathrm{mg}$ ), otro antagonista de los receptores $\mathrm{H}_{2}$ de la histamina, de menor potencia y fabricada en envases con menos tabletas (6 y 12 tabletas). Ambos se conside- 
ran como tratamiento de primera línea equivalente a los antiácidos de aluminio y magnesio para los casos leves de reflujo de ácido y pirosis.

\section{PUBLICACIONES}

\section{Aseguramiento de la calidad de productos farmacéuticos Volumen 1. Ginebra: Organización Mundial de la Salud; 1997, 238 pp. Precio: US $\$ 45,00$; FS 50,00; FS 35,00 en países en desarrollo. ISBN: 9241545046}

Esta obra, que está disponible también en inglés y francés, es un compendio de materias y lineamientos relacionados, algunos ya publicados separadamente como anexos en los informes del Comité de Expertos de Medicamentos. Para la OMS, el aseguramiento de la calidad, seguridad y eficacia de los medicamentos ha sido motivo de continua inquietud. A fin de responder a la necesidad mundial de garantizar como es debido la calidad de los medicamentos, el Comité de Expertos ha hecho durante años numerosas recomendaciones destinadas a promover el buen funcionamiento de las regulaciones nacionales y a controlar los sistemas y la aplicación de estándares establecidos por personal debidamente calificado. El libro constituye una fuente donde se examinan la regulación nacional de los medicamentos; la evaluación y el análisis básico de los productos, su registro sanitario y distribución; la Farmacopea Internacional; los servicios de laboratorio; las marcas internacionales; los productos adulterados, y el entrenamiento de personal en el campo de la farmacología. Este compendio reúne por primera vez los temas referidos, haciéndolos más accesibles, y es de gran utilidad para las facultades de farmacia, las agencias reguladoras y la industria farmacéutica. Su segundo volumen está en preparación.

La publicación puede solicitarse a las agencias autorizadas para la venta de libros de la OMS en los distintos países. Donde no se disponga de tales agencias, se puede solicitar a: World Health Organization, Distribution and Sales, 1211 Geneva 27, Switzerland.

\section{La reforma del sector farmacéutico y del sector salud en las Américas: una perspectiva económica Washington, DC: Organización Panamericana de la Salud, 1998, 101 pp. Distribución gratuita. ISBN 9275322376}

Se trata de una obra que examina, desde una perspectiva amplia, los temas pertenecientes al sector farmacéutico y a su reforma. Busca, además, proporcionar información útil a las autoridades en materia de salud y en el campo financiero, en conformidad con los objetivos especificados en las políticas sanitarias nacionales, para que puedan explorar los temas centrales del sector farmacéutico y actuar debidamente en el contexto de la reforma del sector de la salud.

\section{REFERENCIAS}

Retirada de los anorexígenos fenfluramina y dexfenfluramina. Buttletí Groc. Institut Català de Farmacología. Universitat Autonoma de Barcelona. Vol. 10, No. 5, octubre-diciembre de 1997.
Food and Drug Administration. Talk Paper. 9 de febrero de 1998.

Food and Drug Administration. Talk Paper. 10 de febrero de 1998

Food and Drug Administration. Talk Paper. 27 de febrero de 1998 .

Food and Drug Administration. Press Office. Statement. 10 de marzo de 1998.

Food and Drug Administration. Public health notice. Center for Devices and Radiological Health. 11 de marzo de 1998.

WHO Pharmaceuticals Newsletter. No. 11, noviembre de 1997.

WHO Pharmaceuticals Newsletter. No. 12, diciembre de 1997.

WHO Pharmaceuticals Newsletter. No. 1, enero de 1998.

WHO Pharmaceuticals Newsletter. No. 2, febrero de 1998.

Información farmacológica da a conocer las decisiones oficiales sobre regulación de productos farmacéuticos adoptadas por organismos gubernamentales e internacionales en todo el mundo, los fundamentos científicos en que se sustentan tales decisiones y otros datos de interés relacionados con el tema. Como la mayor parte de la información proviene de fuentes de circulación relativamente limitada, su diseminación en esta forma permite hacerla llegar a un público más amplio. De esta manera se pretende contribuir a limitar el uso irracional de medicamentos y fomentar su uso racional en la Región de las Américas. La sección está a cargo del Programa de Medicamentos Esenciales y Tecnología para la Salud (HSE) de la OPS y se publica en la Revista Panamericana de Salud Pública/ Pan American Journal of Public Health en enero, abril, julio y octubre. Las separatas pueden solicitarse al programa mencionado, Organización Panamericana de la Salud, 525 Twenty-third Street, NW, Washington, DC 20037, EUA. 